\title{
ФАКТОРЫ ВЛИЯНИЯ НА РАСХОЖДЕНИЕ ДАННЫХ СТАТИСТИКИ ВНЕШНЕЙ ТОРГОВЛИ И ИХ ЗНАЧЕНИЕ
}

\section{(C) 2021 Толмачев М.Н.}

доктор экономических наук, руководитель Департамента бизнес-аналитики

Финансовый университет при Правительстве Российской Федерации, Россия, Москва

E-mail:mntolmachev@fa.ru

\section{(C) 2021 Земскова О.Н.}

кандидат экономических наук, доцент Департамента бизнес-аналитики Финансовый университет при Правительстве Российской Федерации, Россия, Москва E-mail: ONZemskova@fa.ru

\section{(c) 2021 Нарбут B. B.}

кандидат экономических наук, доцент Департамента бизнес-аналитики Финансовый университет при Правительстве Российской Федерации, Россия, Москва E-mail:vvnarbut@fa.ru

В статье изучены важные аспекты динамики внешнеторговых отношений актуальные на сегодняшний день, особенно в условиях активизации постоянной санкционной борьбы. Для того чтобы понять, как правильно управлять экспортными и импортными потоками, необходимо узнать основные причины, которые повлияли на внешнеторговую деятельность в прошлом. Знание ключевых факторов помогает сформировать будущую стратегию управления внешней торговли.

Ключевые слова: анализ, аспекты, активизация, внешнеэкономическая деятельность, информация, международный масштаб, национальный разрез, таможенные органы, унификация.

Определение статистики внешнеэкономической деятельности, как в национальном разрезе, так и в международном масштабе - это актуальная проблема. Несмотря на всеобщую унификацию российского внешнеторгового и таможенного законодательства с международными актами и конвенциями возникает большое количество коллизий и нестыковок.

Таможенные органы РФ формируют первичную статистику внешнеэкономической деятельности. Как известно, внешняя торговля состоит из совокупности внешнеэкономических сделок. Таможенные органы получают информацию из первичных документов, сопровождающих внешнеэкономическую сделку.

Для целей статистики внешнеэкономической деятельности следует разделить внешнюю торговлю на взаимную торговлю в рамках Евразийского экономического союза и внешнюю торговлю со странами дальнего и ближнего (СНГ) зарубежья.

Объемы внешней торговли РФ по группам стран, млн. дол., 2020 год представлены на рисунке 1.
Проведя сравнительный анализ по таможенной статистике, представленной на разных ресурсах, можно составить некую сводную таблицу, из которой видно, что данные по внешнеторговому обороту различаются между разными ведомствами (таблица 1).

Конечно, миллионные расхождения в масштабах миллиардных оборотов выглядят довольно небольшими и некритичными, но тем не менее возникает вопрос, почему существующая система обмена информацией между органами приводит к искажению данных.

Анализируя таможенную статистику за 2020 год на одном из интернет-порталов, который ссылается на официальную статистику, можно увидеть, что объемы внешней торговли значительно сократились по сравнению с 2019 годом (таблица 2).

Как видим из таблицы выше, внешнеторговый оборот составил 558,68 млрд. долларов. Можно увидеть, что объемы внешнеторгового оборота уменьшились на $16 \%$ по сравнению с 2019 годом, причем снижение импорта составило 5,3\%, а экспорта - 22\%. Объемы внешней тор-

\footnotetext{
* Статья подготовлена по результатам исследований, выполненных за счет средств по государственному заданию Финуниверситета
} 
600000

500000

494411

400000

300000

200000

100000

73412

0
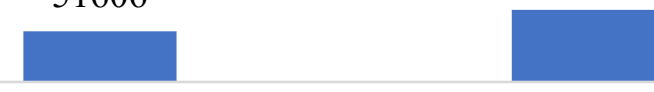

ЕАЭС

Ближнее зарубежье (СНГ)

Дальнее зарубежье

Рисунок 1. Объемы внешней торговли РФ по группам стран, млн. дол., 2020 год

Таблица 1. Внешнеторговая статистика РФ за 2015-2020 годы из разных источников, млн. долл.

\begin{tabular}{|c|c|c|c|c|c|c|c|}
\hline \multicolumn{2}{|c|}{ Организация / Источник } & 2015 & 2016 & 2017 & 2018 & 2019 & 2020 \\
\hline \multirow{2}{*}{ Росстат } & Экспорт & 343512 & 285652 & 357767 & 449564 & - & - \\
\cline { 2 - 9 } & Импорт & 182902 & 182448 & 227464 & 238493 & - & - \\
\cline { 2 - 9 } & Оборот & 526414 & 468100 & 585231 & 688057 & - & - \\
\hline Минэкономразвтия & Оборот & - & - & - & 688057 & 667783 & - \\
\hline ФТС & Оборот & 530428 & 471264 & 587546 & 692566 & 674279 & 571913 \\
\hline Банк России & Оборот & - & - & - & - & 674734 & 571500 \\
\hline $\begin{array}{c}\text { Итоги внешней торговли } \\
\text { России. Аналитика за 2020 } \\
\text { год. (ru-stat.сот) }\end{array}$ & Оборот & - & - & - & - & 668800 & 567800 \\
\hline
\end{tabular}

Таблица 2. Внешняя торговля России в 2020 году, млрд. USD [1]

\begin{tabular}{|c|c|c|c|c|c|c|}
\hline Месяц & Оборот & Изм. \% & Импорт & Изм. \% & Экспорт & Изм. \% \\
\hline $2020-01$ & 46,60 & $-2,80$ & 16,07 & 3,75 & 30,53 & $-5,92$ \\
\hline $2020-02$ & 46,02 & $-12,65$ & 17,67 & 0,61 & 28,34 & $-19,29$ \\
\hline $2020-03$ & 48,92 & $-13,87$ & 19,22 & $-3,83$ & 29,70 & $-19,32$ \\
\hline $2020-04$ & 40,33 & $-29,97$ & 16,60 & $-20,94$ & 23,73 & $-35,16$ \\
\hline $2020-05$ & 37,61 & $-27,12$ & 16,71 & $-12,78$ & 20,90 & $-35,58$ \\
\hline $2020-06$ & 42,72 & $-17,72$ & 18,48 & $-4,56$ & 24,24 & $-25,55$ \\
\hline $2020-07$ & 42,64 & $-22,90$ & 18,83 & $-12,53$ & 23,80 & $-29,51$ \\
\hline $2020-08$ & 42,10 & $-24,16$ & 19,03 & $-9,91$ & 23,06 & $-32,92$ \\
\hline $2020-09$ & 50,17 & $-9,87$ & 19,69 & $-1,82$ & 30,49 & $-14,40$ \\
\hline $2020-10$ & 49,60 & $-15,80$ & 21,32 & $-6,16$ & 28,28 & $-21,85$ \\
\hline $2020-11$ & 52,03 & $-10,03$ & 22,06 & $-0,20$ & 29,98 & $-16,12$ \\
\hline $2020-12$ & 59,94 & $-2,64$ & 24,18 & 6,56 & 35,76 & $-8,02$ \\
\hline
\end{tabular}


говли начали снижаться еще с января 2020 года, то есть до того, как был официально объявлен коронавирус и введены ограничения на работу организаций и перемещение граждан. В таблице 3 представлен товарооборот 2020 г.

На сайте ФТС мы также можем найти таможенную статистику по внешнеторговому обороту России по месяцам за 2019 и 2020 года (рисунок 2 и 3), и цифры снова немного отличаются от тех, что были представлены выше.

При анализе таможенной статистики за март, выявлено, что нефть российского производства продавалась иностранным партнерам по средней цене $\$ 46$ за баррель, что в 1,5 раза выше, чем цена Urals, которая рассчитывается Минфином. Причиной завышения является временной лаг при учете поставок ФТС.

Торговля в рамках интеграционного объединения ЕАЭС имеет свою специфику, поскольку с одной стороны осуществляется экспорт российского товара, сопряженный с вывозом его в другую страну, а с другой стороны фактического таможенного оформления эта сделка не проходит, поскольку отсутствует таможенная граница между странами-участницами ЕАЭС.

Таким образом, в рамках ЕАЭС происходит свободная взаимная торговля субъектов экономической деятельности в соответствии с договором о Евразийском экономическом союзе [3].

Тем не менее, для статистических целей при перемещении товаров внутри ЕАЭС утвержден «Порядок ведения статистики взаимной торговли товарами Российской Федерации с государствами-членами Евразийского экономического союза» [4] [5]. «В соответствии с данным документом статистический учет товаров и внешнеэкономических сделок осуществляется на основе статистических форм учета перемещения товаров» [6].

Исходя из результатов предварительного обзора последствий влияния пандемии COVID-2019 на мировые и внутренние экономические процессы [7], а также общей количественной оценки тенденций развития российской внешней торговли сделаны следующие выводы относительно планируемой работы.

При составлении прогнозов объемов внешней торговли Российской Федерации следует принимать во внимание и количественно учитывать следующие группы факторов, укрупненно представленные в таблице 4.

Таблица 3. Внешнеторговый оборот важнейших товаров, 2020 г.

\begin{tabular}{|c|c|c|c|}
\hline \multirow{2}{*}{} & \multicolumn{3}{|c|}{2020 г. } \\
\cline { 2 - 4 } & млн. долларов США & в \% к 2019 г. & в \% к итогу \\
\hline Экспорт & 336394,0 & 79,3 & 100,0 \\
\hline Импорт & 231430,0 & 94,7 & 100,0 \\
\hline
\end{tabular}

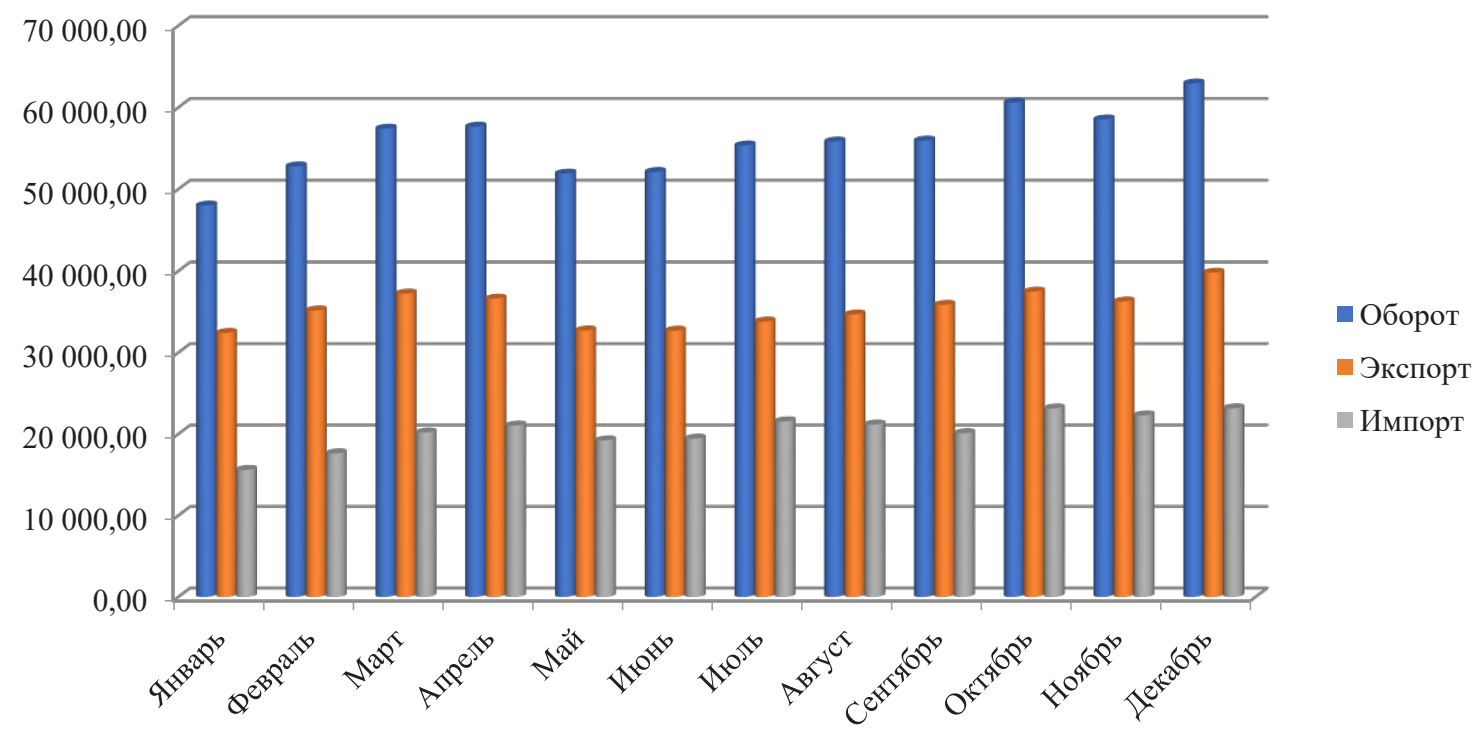

Рисунок 2. Динамика внешней торговли РФ за 2019 гг., млн. долл.[2] 


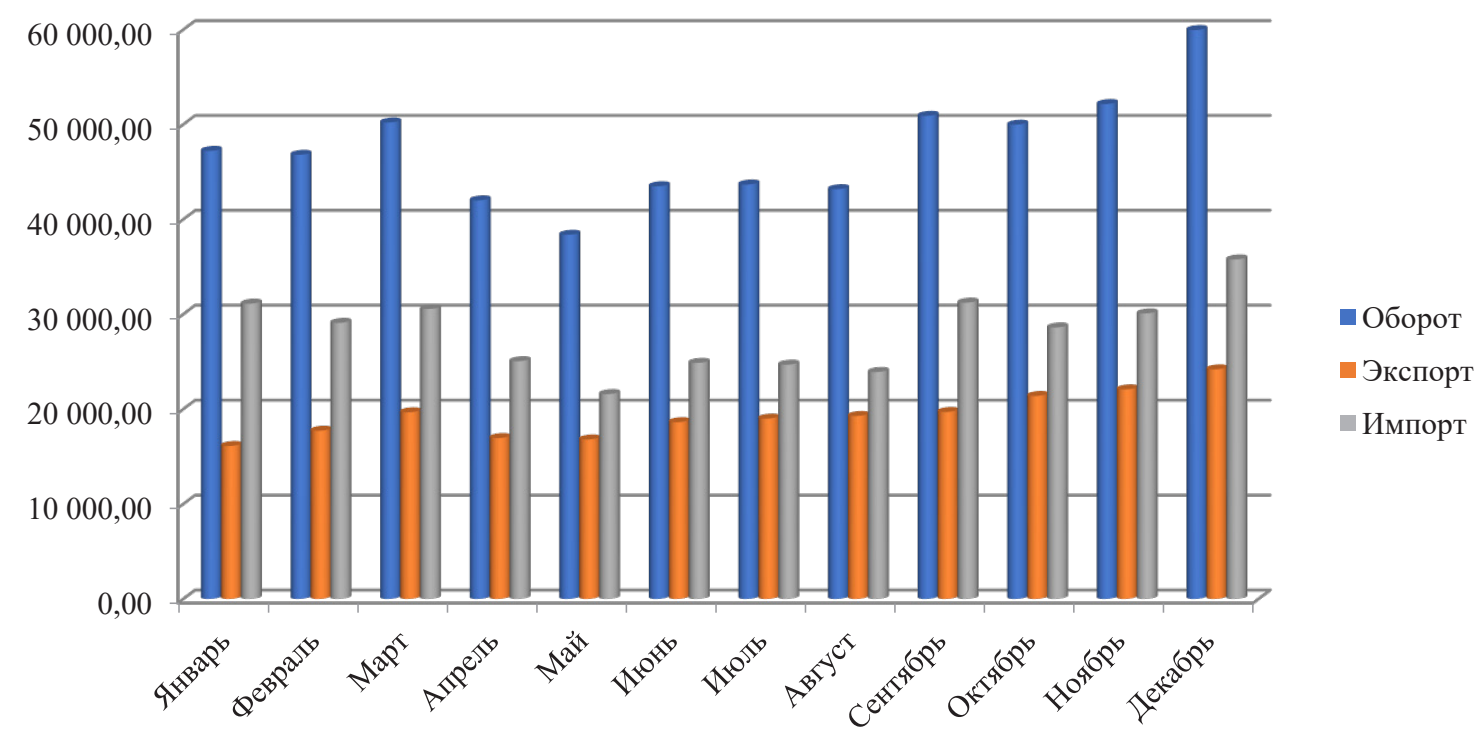

Рисунок 3. Динамика внешней торговли РФ за 2020 гг., млн. долл

Таблица 4. Классификация факторов развития внешней торговли Российской Федерации

\begin{tabular}{|c|c|c|}
\hline Группа факторов & Вид факторов & Источники влияния \\
\hline \multirow{7}{*}{ Экономические } & \multirow{4}{*}{ внешние } & $\begin{array}{l}\text { Общее состояние и развитие экономик других стран, развитие } \\
\text { мировой внешней торговли }\end{array}$ \\
\hline & & Курс валют и драгметаллов, изменения цен на товарные группы \\
\hline & & $\begin{array}{l}\text { Перераспределение и географическое размещение производи- } \\
\text { тельных сил }\end{array}$ \\
\hline & & Развитие процесса цифровизации и информационных технологий \\
\hline & \multirow{3}{*}{ внутренние } & Развитие отдельных видов экономической деятельности \\
\hline & & $\begin{array}{l}\text { Состояние спроса и предложения на внутреннем рынке по груп- } \\
\text { пам товаров и услуг }\end{array}$ \\
\hline & & Состояние и развитие межотраслевых связей \\
\hline \multirow{5}{*}{ Социальные } & \multirow{3}{*}{ внешние } & $\begin{array}{l}\text { Интенсивность распространения и биологического воздействия } \\
\text { эпидемии COVID-19 и эффективность средств ее пресечения }\end{array}$ \\
\hline & & $\begin{array}{l}\text { Организация мер пресечения распространения эпидемии в стра- } \\
\text { нах мира }\end{array}$ \\
\hline & & Состояние систем здравоохранения стран мира \\
\hline & \multirow{2}{*}{ внутренние } & $\begin{array}{l}\text { Организация мер пресечения распространения эпидемии на тер- } \\
\text { ритории Российской Федерации }\end{array}$ \\
\hline & & $\begin{array}{l}\text { Меры поддержки и состояния системы здравоохранения Россий- } \\
\text { ской Федерации }\end{array}$ \\
\hline \multirow{6}{*}{ Политические } & \multirow{4}{*}{ внешние } & Состояние и развитие торговых отношений между странами мира \\
\hline & & $\begin{array}{l}\text { Развитие процессов международной интеграции экономической } \\
\text { деятельности }\end{array}$ \\
\hline & & $\begin{array}{l}\text { Возможности развития международных экономических проектов } \\
\text { Российской Федерации }\end{array}$ \\
\hline & & $\begin{array}{l}\text { Внедрение и/или снятие экономических санкций относительно } \\
\text { отдельных секторов экономики Российской Федерации }\end{array}$ \\
\hline & & Развитие политики импортозамещения \\
\hline & внутренние & $\begin{array}{l}\text { Разработка и выбор стратегических направлений внутренней } \\
\text { политики относительно: } \\
\text { - отраслевого развития; } \\
\text { - научно-технологического развития и инноваций; } \\
\text { - цифровизации; } \\
\text { - регионального развития. }\end{array}$ \\
\hline
\end{tabular}


Для учета факторов, представленных в таблице 4 , нами предусматривается их подробный качественный анализ, выделение и систематизация рисков и потенциальных возможностей развития, с последующим формированием системы показателей как основы составления прогнозов.

Результат сформированной динамики экспорта и импорта России, выделяет такие схожие черты как:

- высокая синхронность на отрезке 19942019 гг., в том числе «провалы» под влиянием кризисов 2008 г. и 2014 г.;

- в 2020 году наблюдается несовпадение фаз, так экспорт значительно снизился, чему стал причиной Covid-19, тогда как динамика импорта осталась на уровне предыдущего года, лишь сбился сезонный цикл. Объяснение расхождений следует находить в области анализа товарной структуры экспорта и импорта.

Показатели, товарооборота, экспорта, импорта и т.д., характеризующие внешнеэкономическую деятельность государств, представляют собой стоимостные величины, что накладывает ограничения на ряд подходов к их анализу, по этой причине перейдем к рассмотрению относительных величин, поделив экспорт (импорт) на ВВП РФ (рисунок 4).

Переход к относительным величинам, позволил нам получить дополнительную информацию о ретроспективной динамике экспорта- импорта и макроэкономической ситуации в стране. Так в начале 1990-х годов наблюдается резкий всплеск импорта относительно ВВП, что объясняется либерализацией экономических процессов и компенсацией внутристранового производства за счет импортных товаров. В свою очередь, роста экспорта относительно ВВП (до 40\%) в начале 2000-х годов объясняется высокими мировыми ценами на углеводороды, что при стабильных объемах, привело к росту показателя в стоимостном выражении.

В заключении отметим, что анализ динамики указывает на необходимость его дополнения рассмотрением структуры экспорта и импорта, что позволит повысить качество выводов относительно изменения траектории движения товаропотоков.

Помимо расхождений таможенной статистики внутри страны нередко возникают расхождения в данных между статистикой ФТС и статистикой стран-партнеров Российской Федерации или международных организаций, анализирующих потоки внешней торговли.

При расхождениях таможенной статистики страны и ее торговых партнеров зачастую начинают предполагать, что внешнеторговое законодательство нарушено. Однако в большинстве случаев это объясняется различиями, существующими в методике работы таможенных ведомств различных государств.

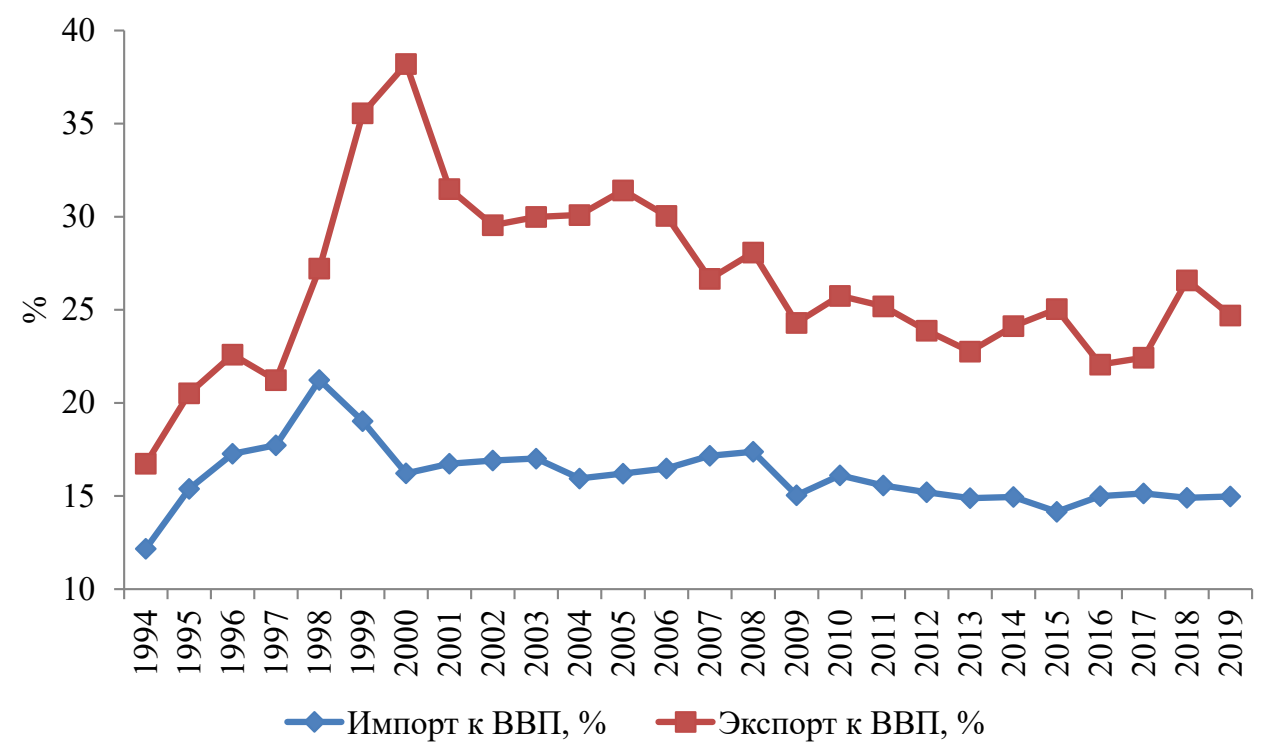

Рисунок 4. Динамика экспорта и импорта, относительно ВВП, \%

Источник: динамика импорта (экспорта) взята с портала Росстата (по методологии платежного баланса); ВВП в долларах США взят с портала Всемирного банка 


\section{Библиографический список}

1. Статистика внешней торговли России/ Источник: https://statimex.ru/ (дата обращения 10.09.2021).

2. Данные ФТС РФ. Указаны цифры, не включая рыбу и морепродукты Российской Федерации, не подлежащие доставке для оформления на территории Российской Федерации; бункерное топливо, горючее и некоторые другие товары.

3. «Договор о Евразийском экономическом союзе» (Подписан в г. Астане 29.05.2014) (ред. от 01.10.2019).

4. Постановление Правительства РФ от 19.06.2020 N 891 «О порядке ведения статистики взаимной торговли товарами Российской Федерации с государствами - членами Евразийского экономического союза и признании утратившим силу постановления Правительства Российской Федерации от 7 декабря 2015 г. N $1329 »$ (вместе с «Правилами ведения статистики взаимной торговли товарами Российской Федерации с государствами - членами Евразийского экономического союза»).

5. Правила ведения статистики взаимной торговли товарами Российской Федерации с государствамичленами Евразийского экономического союза. Утверждены постановлением Правительства Российской Федерации от 19 июня 2020 г. № 891.

6. Белов В.А. Статистическая форма, счет-фактура и грузовая таможенная декларация // Хозяйство и право. Номер: 6 (473) Год: 2016, С.107-111.

7. Arriola, C., et al. «Efficiency and risks in global value chains in the context of COVID-19», OECD Economics Department Working Papers, No. 1637, OECD Publishing, Paris, 2020 // https://doi.org/10.1787/3e4b7ecf-en 